Nikki Lorraine Y. King-Chao, MD

Michael A. Sarte, MD ${ }^{1,2}$

'Department of Otorhinolaryngology

Head and Neck Surgery

The Medical City

Ortigas Ave., Pasig City, Philippines

${ }^{2}$ Department of Otorhinolaryngology

Head and Neck Surgery

Rizal Medical Center

Pasig Blvd., Pasig City, Philippines
Correspondence: Dr. Nikki Lorraine Y. King-Chao

Department of Otorhinolaryngology - Head and Neck Surgery

The Medical City

Ortigas Avenue, Pasig City 1600

Philippines

Phone: (632) 6356789 local 6250

Fax: (632) 6873349

Email: nikkilorrainekingmd@yahoo.com

Reprints will not be available from the author.

The authors declared that this represents original materia that is not being considered for publication or has not been published or accepted for publication elsewhere, in full or in part, in print or electronic media; that the manuscript has been read and approved by all the authors, that the requirements for authorship have been met by each author, and that each author believes that the manuscript represents honest work.

Disclosures: The authors signed disclosures that there are no financial or other (including personal) relationships, intellectual passion, political or religious beliefs, and institutional affiliations that might lead to a conflict of interest.

Presented at the 28th Annual Research Forum, 17th floor Medical Arts Tower, The Medical City, Ortigas Ave., Pasig City, Philippines. December 6, 2012.

Presented at Philippine Society of Otolaryngology Head and Neck Surgery, Analytical Research Contest (2nd Place). October 24, 2013. CET Auditorium, GlaxoSmithKline (GSK) Bldg., Chino Roces Ave., Makati City

\section{Association of Excessive Daytime Sleepiness and Obesity with Apnea-Hypopnea Index in Adult Patients Suspected of Obstructive Sleep Apnea Syndrome}

\begin{abstract}
Objective: To determine whether excessive daytime sleepiness (EDS) as assessed by the Epworth Sleepiness Scale (ESS) is significantly correlated with body mass index (BMI) and Apnea-Hypopnea Index (AHI) in patients suspected of OSAS and whether obesity as assessed by BMI is associated with AHI.
\end{abstract}

\section{Methods:}

\section{Design: Non-concurrent cohort study}

Setting: Tertiary Private Hospital

Population: The charts of 389 patients suspected to have sleep disorders and referred for polysomnography (PSG) at the Center for Snoring and Sleep Disorders in year 2009 were reviewed. Inclusion criteria were patients aged 19 and above with complete data. A total of 238 patient charts were included in the study.

Results: The study included a total of 238 patient charts. Results showed no significant association between ESS and AHI ( $p$-value $>0.05$ ) even when correlated with the different severities of OSAS ( $p$-value $>0.05$ ). Sensitivity and specificity of ESS was found to be $54 \%$ and $57 \%$, respectively, indicating that ESS is not a sensitive and specific tool to predict the presence of OSAS. These findings suggest that ESS may not be able to significantly identify patients with OSAS. However, BMI showed a significant association with ESS ( $p$-value $<0.05)$ representing more patients with EDS belonging to the obese category. Conversely, obese patients were twice more likely to have EDS, represented by ESS scores of $>=10$. BMI was also significantly associated with AHI using oneway Anova test.

Conclusion: This report concludes that the ESS alone is insufficient to identify patients with OSAS. Nevertheless, questionnaires like the ESS supplement relevant history to help diagnose patients with sleep disorders particularly OSAS. On the other hand, the ESS showed a significant association with BMI representing more obese patients had excessive daytime sleepiness. The likelihood ratio of having excessive daytime sleepiness is two times more for obese patients. BMI was also significantly associated with AHI which confirms the well established relationship of obesity with OSAS, and shows that obese patients are at higher risk for severe OSAS.

Keywords: obstructive sleep apnea syndrome, daytime sleepiness, Epworth sleepiness scale, polysomnography, apnea-hypopnea index, body-mass index 
Excessive daytime sleepiness and obesity are some of the prominent symptoms of obstructive sleep apnea syndrome (OSAS). OSAS is characterized by repeated episodes of upper airway obstruction during sleep, nocturnal hypoxemia and sleep fragmentation. ${ }^{1}$ Patients with OSAS are at an increased risk for significant morbidity and mortality such as accidents, cardiovascular events and neurocognitive impairment. Hence, immediate identification of patients with this syndrome is crucial in preventing severe complications such as respiratory distress and sudden death.

Most patients seen at a sleep disorder center complain of excessive daytime sleepiness (EDS). EDS may result in vehicular accidents, poor job performance and adverse consequences in family and quality of life. ${ }^{2}$ According to Johns, "the severity of their chronic daytime sleepiness is an important aspect of each patient's assessment." ${ }^{13} \mathrm{He}$ developed a simple, self-administered questionnaire to determine the subject's general level of daytime sleepiness called the Epworth Sleepiness Scale (ESS). In his study of 180 adult respondents, total ESS scores distinguished normal subjects from patients with a range of sleep disorders. ESS scores were significantly correlated with sleep latency measured during multiple sleep latency test and during polysomnography. ESS scores were also significantly correlated with respiratory disturbance index and minimum $\mathrm{SaO}_{2}$ in overnight PSG recordings of patients diagnosed with OSAS. ${ }^{3}$

However, some studies did not find any significant correlation between ESS score and these polysomnographic parameters. ${ }^{1,4}$ Bixler, et $a .^{2}$ found that excessive daytime sleepiness was more strongly associated with depression and obesity than sleep disorders, and depression was found to be the most significant risk factor for EDS followed by body mass index (BMI), age, typical sleep duration, diabetes and smoking before sleep apnea. On the other hand, Resta, et al. ${ }^{5}$ found that morbid obesity can be associated with excessive daytime sleepiness even in the absence of sleep apnea.

Obesity is a known risk factor for OSAS across different populations. Obesity is commonly measured using body mass index (BMI) defined as an individual's body mass divided by height squared $\left(\mathrm{kg} / \mathrm{m}^{2}\right)$. The World Health Organization (2000) proposed a system of classification for obesity based on BMI with the following categories: underweight, normal, pre-obese and obese. ${ }^{6}$ The National Heart, Lung and Blood Institute (1999) with the same criteria used the following terminologies: underweight, normal, overweight and obese. ${ }^{7}$ In the study by Resta, et al., ${ }^{5}$ OSAS was associated with obesity in more than $50 \%$ of a population of obese patients with a mean BMI higher than 40.0.

This study seeks to determine whether excessive daytime sleepiness (EDS) as assessed by the Epworth Sleepiness Scale (ESS) is significantly associated with Body Mass Index (BMI) and Apnea-Hypopnea Index $(\mathrm{AHI})$ as identified by polysomnography (PSG) to indicate the presence of Obstructive Sleep Apnea Syndrome (OSAS) in suspect patients. The use of the ESS, if found to be significantly correlated with the mentioned variables can help physicians identify patients suspected to have OSAS earlier and shorten delay in management. The ESS may also aid physicians decide whether a PSG is urgently recommended in these patients. It can guide physicians in discerning which patients need proper advice with regards to the risks associated with excessive daytime sleepiness such as motor or work-related accidents. ${ }^{8}$

The specific objectives include assessing the association between EDS using the ESS and AHI together with the different levels of severity of OSAS among those referred to the Center for Snoring and Sleep Disorders in a Tertiary Private Hospital. The study also seeks to ascertain the accuracy of the ESS in predicting presence of OSAS based on AHI by determining sensitivity and specificity of the ESS. It also verifies the association between the ESS and BMI and between AHI and BMI. The likelihood ratio will be determined if there is any significance found between these variables.

\section{METHODS}

A retrospective review of the charts of 389 patients suspected to have sleep disorders and referred for polysomnography (PSG) at the Center for Snoring and Sleep Disorders in a Tertiary Private Hospital in year 2009 was completed. With 95\% level of significance, setting the margin of error at $\pm 5 \%$, the minimum sample size computed was 194 . In this study, 238 patients were included who were adults aged 19 and above with complete data. 151 charts were excluded from the study, of which 99 were adult patients with incomplete data and 52 were pediatric patients below 19 years old. Those included were 170 males (71\%) and 68 females (29\%) with ages ranging between 24 and 81 . The mean age was $44.19 \pm 12.04$ years.

The Center for Snoring and Sleep Disorders is equipped with two patient rooms with one recording machine each and one evaluation room. The following parameters are simultaneously recorded: electroencephalogram, electrooculogram, electromyogram, ECG, oronasal airflow using thermal sensors, oxygen saturation using pulse oximetry, thoracic and abdominal changes using piezoelectric tensions sensors and positional changes. The snoring sound was recorded by attaching a pre-laryngeal microphone. The polysomnography (PSG) was conducted in the sleep laboratory using software of Alice-5-system (Philips Respironics). All patients were asked to complete a database form and to answer the self-administered questionnaire ESS prior to the start of the PSG, thus blinding them to the result of their test. 
Details about their height, weight, neck size, waistline and abdominal girth were also recorded. After acquiring informed consent from each patient, patients were given instructions and were connected to the different recordings. The duration of the sleep study lasted for 9 hours, between 10 p.m. and 7 a.m. for each patient. The results were then scored and interpreted by one sleep specialist who was blinded to the result of the patients' ESS.

According to the International Classification of Sleep Disorders, Second Edition (ICSD-2), there are five principal classifications of sleep-related breathing disorders, namely central sleep apnea syndromes, obstructive sleep apnea syndromes (OSAS), sleep-related hypoventilation/hypoxemic syndromes, sleep-related hypoventilation/ hypoxemia due to medical condition and other sleep-related breathing disorder. ${ }^{9}$ The focus in this study was OSAS which is more prevalent and beneficial when diagnosed early. OSAS is further categorized as obstructive sleep apnea in adult and pediatric patients. Obstructive sleep apnea is defined as repetitive episodes of complete (apnea) or partial (hypopnea) upper airway obstruction occurring during sleep. Apneic and hypopneic events should last at least 10 seconds which can occur in any stage of sleep. ${ }^{9}$

According to the American Academy of Sleep Medicine (AASM) in the Manual for Scoring of Sleep and Associated events ${ }^{10}$ published in 2007, hypopnea has a recommended and alternative definition. The recommended definition is similar to the definition stated in the AASM 2001 position paper: hypopnea scoring is described as $\geq 30 \%$ reduction in nasal pressure signal excursions and associated $\geq 4 \%$ desaturation from baseline. The alternative definition includes $\geq 50 \%$ reduction in nasal pressure signal excursions from baseline and associated $\geq 3 \%$ desaturation or arousal. Both definitions include a duration of at least 10 seconds or more. Either definition can be used at the discretion of the clinician or investigator. ${ }^{10,11}$ Ruehland, et al. compared AHIs derived using 3 standard hypopnea definitions published by AASM and found out that the use of different definitions led to marked differences in AHI. ${ }^{11}$ In its latest definition, hypopnea is defined as reduction of breathing amplitude by $\geq 30 \%$ for at least 10 seconds or more and oxygen desaturation of $\geq 3 \% .{ }^{12}$ In this study, the alternative definition for hypopnea was used in scoring the sleep study results.

In this article, the Apnea-Hypopnea Index (AHI) was used to represent the presence or severity of OSAS. The most widely used criteria to represent different levels of OSAS based on AHI were adapted in this study. AHI which is the averaged frequency of apnea and hypopnea events per hour of sleep is defined as the following: mild sleep apnea if the $\mathrm{AHI}$ is 5 to 15 events per hour; moderate if the value is more than
15 to 30 events per hour; and severe if $\mathrm{AHI}$ is greater than 30 events per hour. $9,11,13$

Body mass index (BMI) as categorized by the International Obesity Task Force of WHO is classified as underweight, normal, pre-obese and obese. ${ }^{6}$ In this study, the terminologies used by the National Heart, Lung and Blood Institute were applied namely underweight, normal, overweight and obese. ' Underweight is defined as a BMI of less than 18.5; normal is within the range of 18.5 to 24.9 ; overweight ranges from 25 to 29.9 while obesity is a BMI of greater than 30 . BMI was gathered from the patients' charts and used to represent obesity which is also an important risk factor for OSAS.

To quantify daytime sleepiness, the Epworth Sleepiness Scale (ESS) developed by Murray Johns was applied in this study. ${ }^{3}$ It is a simple, selfadministered questionnaire composed of eight situations to assess a subject's chance of dozing off in that particular scenario. Each situation is graded from 0 to 3 with 0 as having no chance of dozing off and 3 representing a high chance of falling asleep. The score for each situation in the ESS was added to give a total score of 0 to $24 .{ }^{3}$ The ESS was found to have a high sensitivity $(93.5 \%)$ and high specificity (100\%) with a cut-off score $>10 .{ }^{14}$ In this study, the cut-off score of less than 10 was used to mean a negative result or absence of daytime sleepiness while more than or equal to 10 as a positive result or presence of daytime sleepiness. ${ }^{15,16,17}$

The ESS has been validated in several studies. According to Johns, the ESS was the most discriminating test among the three of the most commonly used tests to assess excessive daytime sleepiness namely multiple sleep latency test, maintenance of wakefulness test and ESS. ${ }^{14}$ The ESS has also been translated into different languages (Filipino, Italian, Chinese, Spanish and Greek) and has been ascertained to have high construct validity, test-to-test reliability and internal consistency. In a local study by Albay, et al., ${ }^{18}$ the validity of the Filipino version was established based on internal consistency and construct reliability. The Cronbach's alpha was computed at 0.577 which was lower compared to that of the original English version of the ESS. Nonetheless, it is still considered acceptable since most surveys use the value of more than 0.45 , confirming it as internally consistent and valid. In this study, the English version of the ESS was used which had a high Cronbach's alpha. This finding was similar to other studies abroad further validating its clinical use in English-literate patients. ${ }^{18}$

The study applied a retrospective cohort design using data found in the patients' records. All data were stored and retrieved electronically 
from the sleep laboratory. Data gathered included the patients' age, sex, height, weight, BMI, neck size, waistline, abdominal girth, baseline and lowest oxygen saturation, $\mathrm{AHI}$ and ESS. All data were recorded and tabulated in Excel worksheet (Microsoft Office Excel 2007). Under these circumstances, permission from the Institutional Review Board was requested to use the data for research purposes ensuring patient confidentiality in data collection by assigning numerical values. Data collection and tabulation were facilitated by the sleep laboratory technician. Data analysis was accomplished by a statistician. Continuous variables were presented in mean \pm standard deviation while categorical variables were presented in count (percentages \%). Comparisons between groups of patients with and without excessive daytime sleepiness were statistically determined using Chi-square test and independent T-tests. For association between two categorical variables, Chi-Square Test was conducted. For continuous variables with two groups, independent T-tests were used and for continuous variables with more than two groups, Anova Test was applied. Statistical significance was defined as $p<0.05$. The odds ratio was computed at $95 \%$ confidence interval for significant variables. Accuracy tests were done using sensitivity and specificity analysis.

\section{RESULTS}

Table 1 shows the main demographic characteristics of the patients included in the study categorized according to the presence or absence of EDS. Age, gender distribution, neck circumference, baseline and lowest $\mathrm{SaO}_{2}$ were similar in both groups. ESS, BMI, waistline and abdominal girth were found to have significant difference between the two groups.

Table 2 presents the correlation of ESS with the polysomnographic variable $\mathrm{AHI}$ compared using Chi-square test to determine significant association. The results show that there is no significant association between ESS and $\mathrm{AHI}$ ( $p$-value 0.152, siginificant if $p$-value $<0.05$ ). The findings suggest that ESS may not be able to significantly identify patients with OSAS.

Table 3 illustrates the correlation of ESS with AHI according to the different severities of OSAS: mild, moderate and severe using Chisquare test. The findings are consistent with Table 2 and demonstrate no significant difference between ESS and different levels of OSAS which means that ESS cannot distinguish between different severities of OSAS.

Table 4 shows the sensitivity and specificity analysis of ESS in identifying patients with OSAS based on $\mathrm{AHI}$. The results reveal that
Table 1. Demographic characteristics of patients with and without EDS

\begin{tabular}{|l|c|c|c|c|}
\cline { 1 - 3 } & $\begin{array}{c}\text { Total } \\
\boldsymbol{n}=\mathbf{2 3 8}\end{array}$ & $\begin{array}{c}\text { EDS } \\
\boldsymbol{n}=\mathbf{1 2 0}\end{array}$ & $\begin{array}{c}\text { No EDS } \\
\boldsymbol{n}=\mathbf{1 1 8}\end{array}$ & $\boldsymbol{p}$ value* \\
\cline { 1 - 4 } Age & $44.19 \pm 12.04$ & $43.25 \pm 11.32$ & $45.14 \pm 12.71$ & NS \\
\hline Gender & $170(71 \%)$ & $85(71 \%)$ & $85(72 \%)$ & \multirow{2}{*}{ NS } \\
\cline { 1 - 4 } Male & $68(29 \%)$ & $35(29 \%)$ & $33(28 \%)$ & \\
\hline Female & $15.72 \pm 1.91$ & $15.94 \pm 1.88$ & $15.5 \pm 1.92$ & NS \\
\hline Neck Circumference & $38.52 \pm 5.65$ & $39.74 \pm 5.74$ & $37.26 \pm 5.29$ & 0.001 \\
\hline Waistline & $39.03 \pm 5.82$ & $40.28 \pm 6.17$ & $37.73 \pm 5.15$ & 0.001 \\
\hline Abdominal Girth & $29.43 \pm 14.14$ & $31.47 \pm 18.33$ & $27.33 \pm 7.31$ & 0.025 \\
\hline BMl & $97.37 \pm 5.94$ & $96.77 \pm 8.21$ & $97.98 \pm 1.58$ & NS \\
\hline Baseline 02\% & $76.42 \pm 23.63$ & $74.55 \pm 22.87$ & $78.31 \pm 24.33$ & NS \\
\hline Lowest 02\% & $11.04 \pm 5.56$ & $15.28 \pm 3.96$ & $6.72 \pm 3.07$ & 0.000 \\
\hline ESS score
\end{tabular}

Continuous Variables presented in Mean \pm Standard Deviation

Categorical Variables presented in Count (Percentage\%)

NS: nonsignificant,

${ }^{*} p$-value $<0.05$

Table 2. Correlation of ESS with AHI

\begin{tabular}{|c|c|c|c|c|}
\hline & \multicolumn{3}{|c|}{ ESS } & \multirow[b]{2}{*}{$p$-value } \\
\hline AHI & $\begin{array}{l}\text { Negative } \\
\begin{array}{c}\text { n } \\
\text { (\%) }\end{array}\end{array}$ & $\begin{array}{l}\text { Positive } \\
\mathrm{n} \quad(\%)\end{array}$ & $\begin{array}{l}\text { Total } \\
\mathrm{n} \quad(\%)\end{array}$ & \\
\hline Negative & $39 \quad$ (33) & $29 \quad(24)$ & $68 \quad(29)$ & \multirow{3}{*}{0.152} \\
\hline Positive & $\begin{array}{ll}79 \quad(67) \\
\end{array}$ & $91 \quad$ (76) & $170 \quad(71)$ & \\
\hline Total & $118 \quad(50)$ & $120 \quad(50)$ & $238(100)$ & \\
\hline
\end{tabular}

Compared using Chi-square test, significant variable if $p$-value $<0.05$

Table 3. Correlation of ESS and AHI (categorized to mild, moderate and severe)

\begin{tabular}{|c|c|c|c|c|}
\hline & & \multicolumn{2}{|c|}{ ESS scores } & \\
\hline $\begin{array}{l}\text { Apnea-Hypopnea } \\
\text { Index (AHI) }\end{array}$ & $\begin{array}{l}n=238 \\
n \quad(\%)\end{array}$ & $<10$ & $\geq 10$ & $p$-value \\
\hline Negative OSA $(<5)$ & $68 \quad(29)$ & $39 \quad$ (33) & $29 \quad(24)$ & \multirow{5}{*}{0.291} \\
\hline Positive OSA & $170 \quad(71)$ & $79 \quad(67)$ & $91 \quad$ (76) & \\
\hline Mild (5-14) & $38 \quad(16)$ & $20 \quad(17)$ & $18 \quad(15)$ & \\
\hline Moderate (15-30) & $42 \quad(17)$ & $21 \quad(18)$ & $21 \quad$ (18) & \\
\hline Severe $(>30)$ & $90 \quad$ (38) & $38 \quad(32)$ & $52 \quad(43)$ & \\
\hline
\end{tabular}

Compared using Chi-square test, significant variable if $p$-value $<0.05$

ESS is not a sensitive and specific tool to predict elevated AHI and the presence of OSAS with a sensitivity of only $54 \%$ and specificity of $57 \%$. Positive predictive value is at $76 \%$ implying that only $76 \%$ of patients with OSA will have excessive daytime sleepiness and yield a positive 
Table 4. Accuracy tests for ESS to predict OSAS based on AHI

\begin{tabular}{|c|c|c|}
\hline & (n) & $\%$ \\
\hline Positive Predictive Value & $(91 / 120)$ & 76 \\
\hline Negative Predictive Value & $(39 / 118)$ & 33 \\
\hline False Positive & $(29 / 68)$ & 43 \\
\hline False Negative & $(79 / 170)$ & 46 \\
\hline Sensitivity & $(91 / 170)$ & 54 \\
\hline Specificity & $(39 / 68)$ & 57 \\
\hline
\end{tabular}

score $(\geq 10)$ in the ESS. Negative predictive value is at 33\% which means that $33 \%$ of patients with a negative ESS score $(<10)$ will not have OSAS. False positive rate is at $43 \%$ which is the proportion of subjects without OSAS who will yield a positive ESS score while false negative rate is $46 \%$ which is the proportion of subjects with OSAS who will have a negative or low ESS score.

Table 5 demonstrates the relationship of the ESS with the different categories of BMI namely underweight, normal, overweight and obese. The results reveal a significant difference between the BMI of patients with EDS and without EDS ( $p$-value $=0.025$ ). More patients with ESS score of ${ }^{3} 10$ belong to the obese category than those with scores of $<10$ ( $p$-value $<0.05)$. There was no significant difference in the ESS scores of patients who were underweight, normal or overweight. Based on the significant association of ESS score of ${ }^{3} 10$ with the obese category, odds ratio was computed with a confidence interval of $95 \%$. The results show that those who fall in the obese category are two times more likely to have ESS scores of $\geq 10$.
Table 6 illustrates the correlation of the different categories of BMI namely underweight, normal, overweight and obese with different levels of AHI. The results reveal a significant correlation between the $\mathrm{AHI}$ and $\mathrm{BMI}$ ( $p$-value $=0.002$ using one-way Anova). Most patients with normal BMI had AHI score of $<5$ which is negative for OSAS. On the other hand, majority (59.04\%) of obese patients (BMl>30) had $\mathrm{AHI}$ of $>30$ representing severe OSAS.

Table 6. Correlation of AHI and BMI using One-Way Anova

\begin{tabular}{|c|c|c|c|c|c|}
\hline & \multicolumn{4}{|c|}{ ESS scores } & $p$-value \\
\hline AHI & $\begin{array}{c}\text { Underweight } \\
\begin{array}{c}(17.00-18.49) \\
n=6^{*} \\
n \quad(\%)\end{array}\end{array}$ & $\begin{array}{c}\text { Normal } \\
(18.50-24.99) \\
n=61 \\
n \quad(\%)\end{array}$ & \begin{tabular}{|c|}
$\begin{array}{c}\text { Overweight } \\
(25.00-29.99) \\
n=84 \\
n \quad(\%)\end{array}$
\end{tabular} & $\begin{array}{c}\text { Obese } \\
(\geq 30) \\
n=83 \\
n \quad(\%)\end{array}$ & \multirow{5}{*}{$0.002^{* *}$} \\
\hline Negative osa $(<5)$ & 2 (33.33) & 32 (52.46) & $24(28.57)$ & $10(12.05)$ & \\
\hline Mild (5-14) & $2 \quad(33.33)$ & $11(18.03)$ & $16(19.05)$ & $9(10.84)$ & \\
\hline Moderate (15-30) & 1 (16.67) & $9(14.75)$ & 15 (17.86) & 15 (18.07) & \\
\hline Severe $(>30)$ & $1 \quad(16.67)$ & 9 (14.75) & 29 (34.52) & $49(59.04)$ & \\
\hline
\end{tabular}

*Read with caution, small base

**P-value computed using One-Way Anova; significant $p$-value is $<0.05$

Table 7 elaborates on the significant correlation between BMI and AHI. Further statistical analysis using Post-hoc Tukey HSD test was conducted to determine the specific levels which had significant values using the one-way Anova in Table 6. Subset 1 shows that negative, mild and moderate OSAS are homogeneous. Alternatively, subset 2 exemplifies homogeneity among mild, moderate and severe OSAS. Comparison of the subsets reveal a significant difference between negative $(\mathrm{AHI}<5)$ and severe OSAS ( $\mathrm{AHI}>30)$.

Table 5. Correlation of ESS and BMI (based on WHO criteria for Asian population) using Chi-Square test to compare BMI of patients with and without EDS. Odds ratio included for BMl as risk factor to EDS.

\begin{tabular}{|c|c|c|c|c|c|c|}
\hline \multirow[b]{3}{*}{ Body Mass Index (kg/m2)* } & \multicolumn{3}{|c|}{ ESS scores } & \multirow{3}{*}{$p$-value } & & \\
\hline & $n=238$ & $<10$ & $\geq 10$ & & \multicolumn{2}{|c|}{ ESS scores } \\
\hline & $29.43 \pm 14.14$ & $27.33 \pm 7.31$ & $31.47 \pm 18.33$ & & Odds Ratio & 95\% Cl for OR \\
\hline Underweight (17.00-18.49) & $6 \quad(3 \%)$ & $4 \quad(3 \%)$ & $2(2 \%)$ & \multirow{4}{*}{$0.025^{*}$} & \multirow[t]{2}{*}{ reference } & \multirow[t]{2}{*}{ reference } \\
\hline Normal (18.5-24.9) & $61 \quad(26 \%)$ & $36 \quad(31 \%)$ & $25 \quad(21 \%)$ & & & \\
\hline Overweight (25-29.9) & $84 \quad(36 \%)$ & $45 \quad(39 \%)$ & $39 \quad(33 \%)$ & & 1.26 & $(0.64,2.48)$ \\
\hline Obese $(>30)$ & $83 \quad(35 \%)$ & $30 \quad(26 \%)$ & $53 \quad(45 \%)$ & & $2.07^{* *}$ & $(1.21,3.55)$ \\
\hline
\end{tabular}

*P-value computed using Chi-Square Test, Underweight and Normal combined in the analysis.

${ }^{*} p$-value $<0.05$

**Obese category are 2 times more likely to have ESS Scores $\geq 10$ (Final Odds Ratio) 
Table 7. Homogeneous Subsets computed using Tukey HSDa,b

\begin{tabular}{|c|c|c|c|c|}
\hline \multirow{2}{*}{\multicolumn{2}{|c|}{ AHI }} & \multirow{2}{*}{$\begin{array}{c}\text { BMI } \\
\mathrm{N}\end{array}$} & \multicolumn{2}{|c|}{ Subset for alpha $=0.05$} \\
\hline & & & 1 & 2 \\
\hline Negative OSA & $(<5)$ & 68 & 25.78 & \\
\hline Mild & $(5-14)$ & 38 & 26.70 & 26.70 \\
\hline Moderate & $(15-30)$ & 41 & 28.82 & 28.82 \\
\hline Severe & $(>30)$ & 88 & & 33.70 \\
\hline Sig. & & & .67 & .05 \\
\hline
\end{tabular}

Means for groups in homogeneous subsets are displayed.

a. Uses Harmonic Mean Sample Size $=52.100$.

b. The group sizes are unequal. The harmonic mean of the group sizes is used. Type I error levels are not guaranteed.

\section{DISCUSSION}

Controversy exists in the relation of excessive daytime sleepiness as measured by ESS with polysomnographic variables such as $\mathrm{AHI}$, oxygen desaturation index, sleep arousal and sleep fragmentation found in patients with OSAS. Some studies found a favorable correlation with these variables ${ }^{3,15,17}$ while others found no evidence of significant association., 2, 8 In a study by Roure, et al., ${ }^{16}$ consecutive patients $(n=2,882)$ with AHI score of more than five were evaluated. EDS was assessed using ESS and was correlated to $\mathrm{AHI}$. The study found that patients with EDS had slightly higher AHI $(p<0.005)$ and arousal index $(p<0.001)$ and lower nadir oxygen saturation $(p<0.01) .{ }^{16}$ The present study was conducted to contribute evidence to the correlation of ESS with AHI and BMI. The results show no significant correlation was established between ESS and AHI scores in patients with OSAS. But a significant association was noted between ESS scores and BMI.

The results of the present study could be partially explained by the fact that a subjective self-administered questionnaire like the ESS is dependent on the subject's personality traits, emotional factors, quality and quantity of sleep the previous night and understanding of the gravity of excessive sleepiness. ${ }^{15}$ Another possible explanation is the sample population was taken from a sleep laboratory rather than a community population in which case some patients may be in denial of their symptoms and underestimate their sleepiness problem while others may not be aware of their daytime sleepiness. Walter et al. found that some patients have a tendency to underestimate EDS as compared with their bed partners..$^{19}$ Other patients may be so focused on the prominent symptoms of OSAS such as loud snoring or breathing cessation that they fail to notice their daytime sleepiness until they encounter vehicular accidents while others keep themselves awake by focusing on active tasks. On the other hand, Bixler et al. concluded that the presence of EDS is more strongly associated with depression and metabolic factors than with sleep-disordered breathing. ${ }^{2}$ The present study also found that ESS has low sensitivity and specificity in identifying patients with OSAS as evidenced by a rate of $54 \%$ and $57 \%$, respectively. On the contrary, Johns found a high sensitivity and specificity score for ESS at $93.5 \%$ and $100 \%$, respectively with a cut-off score of $>10 .{ }^{14}$ Correlation of ESS with the different levels of OSAS based on the AHI showed that ESS could not distinguish between different severities of OSAS ${ }^{20}$ as opposed to the findings of Johns. ${ }^{3}$

Obesity is one of the major risk factors for OSAS as well as of excessive daytime sleepiness. ${ }^{2}$ Obesity is commonly measured using body mass index. In this study, BMI was correlated with ESS. The results reveal a significant difference between the BMI of patients with EDS and without EDS and show that more patients with EDS are in the obese category. The findings of this study also show that those in the obese category are two times more likely to have ESS scores of ${ }^{3} 10 \mathrm{implying}$ that obese patients are twice more likely to have excessive daytime sleepiness than those who are not obese. These results are supported by the evidences found by Resta and his group that severe obesity even in the absence of OSAS is associated with sleep-related disorders and EDS. All sleep-related symptoms such as apneas, awakenings, choking and unrefreshing sleep were significantly more frequent in obese patients than controls. ${ }^{21}$ The significant difference in waistline and abdominal girth support the findings of a statistical difference in BMI between the two groups. Sleep apnea patients were found to have a greater amount of visceral fat compared to obese controls ( $p$-value $<0.05$ ) and indexes of sleep-disordered breathing were significantly correlated with visceral fat. ${ }^{22}$

In a local study by Mendoza and colleagues, an association between BMI, neck circumference and sleep-disordered breathing was demonstrated suggesting that BMl, weight and neck circumference can be used as clinical predictors of OSAS. ${ }^{23}$ The findings in this study agree with their results and show significant association between BMI and AHI especially for patients with severe OSAS. These findings confirm the well established relationship of obesity as a major predictor of OSAS. ${ }^{24}$ This association is also prevalent in Asians as exhibited by populationbased epidemiological studies in which an increase in BMI has been consistently associated with an increase in AHI. ${ }^{25}$

This study concludes that the ESS is insufficient to identify patients with OSAS. Nevertheless, subjective data evaluated by questionnaires such as ESS contribute supplementary information combined with 


\section{ORIGINAL ARTICLES}

clinical symptoms to select patients who are candidates for further work-ups. The ESS is particularly useful for clinicians with limited access to more complicated sleep diagnostics such as polysomnography or for patients who need subsequent referrals to sleep specialists. With the adverse impact of EDS on quality of life and patient safety, further studies are necessary to identify more sensitive measures of sleepiness specifically in patients with OSAS. Patients with EDS should also be assessed for other factors to identify further differentials such as depression and metabolic disorders, particularly obesity and diabetes. The results show obese patients are two time more likely to have EDS. The findings in this investigation also confirm the well established relationship of obesity with OSAS and show that obese patients are at higher risk for severe OSAS.

\section{APPENDIX}

\section{Epworth Sleepiness Scale}

Name:

Date:

Your age: $(Y r)$ Your sex: $\square$ Male $\square$ Female

How likely are you to doze off or fall asleep in the situations described below, in contrast to feeling just tired?

This refers to your usual way of life in recent times.

Even if you haven't done some of these things recently try to work out how they would have affected you.

Use the following scale to choose the most appropriate number for each situation:-

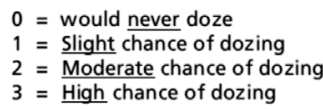

Situation

Chance of dozing

Sitting and reading

Watching TV

As a passenger in a car for an hour without a break .............

Lying down to rest in the afternoon when circumstances permit .....

Sitting and talking to someone...

Sitting quietly after a lunch without alcohol ....................

In a car, while stopped for a few minutes in the traffic

Total

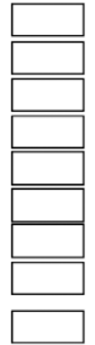

Score:

0-10 Normal range

10-12 Borderline

12-24 Abnormal

The ESS used in this study is reproduced here with the written persmission of Dr. Murray Johns.

\section{ACKNOWLEDGEMENTS}

The authors acknowledge the contribution of Ms. Diana Locayon in the form of statistical consultation and statistical analysis of the data. They also acknowledge the following clinica investigators: Dr. Eris Llanes and Dr. Emilio Acosta, who served as scientific advisors, and Dr. Sarah Moral, who critically reviewed the study proposal.

\section{REFERENCES}

1. Bausmer U, Gouveris H, Selivanova O, Goepel B, Mann EWl. Correlation of the Epworth Sleepiness Scale with respiratory sleep parameters in patients with sleep-related breathing disorders and upper airway pathology. Eur Arch Otolaryngol.2010 Oct; 267(10): 1645-1647.

2. Bixler EO, Vgontzas AN, Lin HM, Calhoun SL, Vela-Bueno A, Kales A. Excessive daytime sleepiness in a general population sample: the role of sleep apnea, age, obesity, diabetes and depression J Clin Endocrinol Metab. 2005 Aug; 90(8): 4510-4515.

3. Johns MW. A new method for measuring daytime sleepiness: the Epworth sleepiness scale. Sleep.1991 Dec; 14(6): 540-545.

4. Chervin RD, Aldrich MS. The Epworth Sleepiness Scale may not reflect objective measures of sleepiness or sleep apnea. Neurology. 1999 Jan 1; 52(1): 125-131.

5. Resta O, Foschino-Barbaro MP, Legari G, Talamo S, Bonfitto P, Palumbo A, et al.Sleep-related breathing disorders, loud snoring and excessive daytime sleepiness in obese subjects. IntJ Obes Relat Metab Disord. 2001 May; 25(5): 669-675.

6. World Health Organization: Obesity, Preventing and Managing the Global Endemic. WHO Technical Report Series no 894, 2000; WHO, Geneva.

7. Clinical Guidelines on the Identification, Evaluation and Treatment of Overweight and Obesity in Adults-The Evidence Report. National Institutes of Health. Obes Res. 1998 Sep; 6 Suppl 2:51S 2095.

8. Sauter C, Asenbaum S, Popovic R, Bauer H, Lamm C, Klosch G, et al. Excessive daytime sleepiness in patients suffering from different levels of obstructive sleep apnea syndrome. JSleep Res. 2000 Sep; 9(3): 293-301.

9. Hauri PJ. American Academy of Sleep Medicine Task Force. International classification of sleep disorders, 2nd ed: Diagnostic and Coding Manual. American Academy of Sleep Medicine, Westchester, IL 2005.

10.Iber C, Ancoli-Israel S, Chesson A, Quan S. for the American Academy of Sleep Medicine. 1st ed. Westchester: IL: American Academy of Sleep Medicine; 2007. The AASM manual for the scoring of sleep and associated events: rules, terminology and technical specifications.

11. Ruehland WR, Rochford PD, O'Donoghue FJ, Pierce RJ, Singh P, Thornton AT. The New AASM criteria for scoring hypopneas: impact on the apnea hypopnea index. Sleep. 2009 Feb; 32(2): 150-157.

12. Berry RB, Brooks R, Gamaldo CE, Harding SM, Marcus CL, Vaughn BV. For the American Academy of Sleep Medicine. 2nd ed. Dariel, IL: American Academy of Sleep Medicine; 2013. The AASM manual for the scoring of sleep and associated events: rules, terminology and technica specifications version 2.0.1.

13. Sleep-related breathing disorder in adults: recommendations for syndrome definition and measurement techniques in clinical research. The Report of an American Academy of Sleep Medicine Task Force. Sleep. 1999 Aug 1; 22(5): 667-89.

14.Johns MW. Sensitivity and specificity of the multiple sleep latency test (MSLT), the maintenance of wakefulness test and the Epworth sleepiness scale: Failure of the MSLT as a gold standard Sleep Res. 2000 Mar; 9(1): 5-11.

15.Sun Y, Ning Y, Huang L, Lai F, Li Z, Zhou G, et al. Polysomnographic characteristics of daytime sleepiness in obstructive sleep apnea syndrome. Sleep Breath. 2012 Jun; 16(2): 375-381.

16. Roure N, Gomez S, Mediano O, Duran J, Peña Mde L, Capote F, et al. Daytime sleepiness and polysomnography in obstructive sleep apnea patients. Sleep Med. 2008 Oct; 9(7): 727-731.

17. Mediano O, Barcelo A, De la Peña M, Gozal D, Aqusti A, Barbe F. Daytime sleepiness and polysomnographic variables in sleep apnoea patients. Eur Respir J. 2007 Jul; 30(1): 110-113.

18. Albay AB Jr, Sison CM, Jorge MC II. Validation of the Filipino version of the Epworth Sleepiness Scale. Phil J Chest Dse. 2008; 14(2): 84-88.

19.Walter TJ, Foldvary N, Mascha E, Dinner D, Golish J.. Comparison of Epworth Sleepiness Scale Scores by patients with obstructive sleep apnea and their bed partners. Sleep Med. $2002 \mathrm{Jan}$; 3(1): 29-32.

20.Smolley LA, Ivey C, Farkas M, Faucette E, Murphy S. Epworth sleepiness scale is useful for monitoring daytime sleepiness. Sleep Res. 1993; 22: 389.

21. Resta O, Foschino Barbaro MP, Bonfitto P, Giliberti T, Depalo A, Pannacciulli N, et al. Low sleep quality and daytime sleepiness in obese patients without obstructive sleep apnea syndrome. $J$ Intern Med. 2003 May; 253(5): 536-543.

22.Vgontzas AN, Papanicolaou DA, Bixler EO, Hopper K, Lotsikas A, Lin HM, et al. Sleep apnea and daytime sleepiness and fatigue: relation to visceral obesity, insulin resistance, and hypercytokinemia. J Clin Endocrinol Metab. 2000 Mar; 85(3): 1151-1158.

23. Mendoza MR, Cal JH, Dela Cruz BO, Guzman-Banzon AV, Limpin MEB, Lao LY, et al. Association of Snoring, Obesity and Daytime Sleepiness with Severity of Sleep-Disordered Breathing. Phil Heart Center J. 2006; 12(3): 40-47.

24. Young T, Peppard PE, Gottlied DJ. Epidemiology of obstructive sleep apnea: a population health perspective. Am J Respir Crit Care Med. 2002 May; 165 (9): 1217-1239.

25.Lam B, Lam DC, Ip MS. Obstructive sleep apnoea in Asia. Int J Tuberc Lung Dis. 2007 Jan; 11(1): 2-11. 